\title{
Intermittent auscultation in obstetric practice in tertiary health facilities in Nigeria. Are we doing it correctly?
}

\author{
Green Kinikanwo ${ }^{1}$, Mkpe Abbey ${ }^{2 *}$, George M. Ela ${ }^{2}$
}

\begin{abstract}
${ }^{1}$ Department of Obstetrics and gynaecology, University of Port Harcourt Teaching Hospital, Port Harcourt
${ }^{2}$ Department of obstetrics and gynaecology, Rivers State University Teaching Hospital, Port Harcourt
\end{abstract}

Received: 03 November 2021

Accepted: 09 December 2021

\section{*Correspondence:}

Dr. Mkpe Abbey,

E-mail: mkpeabbey@aol,com

Copyright: (C) the author(s), publisher and licensee Medip Academy. This is an open-access article distributed under the terms of the Creative Commons Attribution Non-Commercial License, which permits unrestricted non-commercial use, distribution, and reproduction in any medium, provided the original work is properly cited.

\begin{abstract}
Background: Intermittent auscultation (IA) was the main method of foetal monitoring in Nigeria, with the pinard stethoscope more in use than the hand-held Doppler. Aim of the study to produce a guideline on IA, conduct an audit on its use and to give a recommendation for future practice.

Methods: A mixed-method design-observational-descriptive, review and an audit carried out in tertiary centres in Rivers State, Nigeria. The WHO 2018, FIGO 2015 and other guidelines on IA were reviewed. Good practice points were extracted from the literatures and used to produce a guideline. 17 review criteria for the audit were chosen from the guideline and used to test 150 doctors, midwives and nurses. Data were analysed with Epi. info 2020.

Results: A guideline on IA was created. Out of the 150 participants, correct answers to the questions were given as follows: foetal movements over the preceding 24 hours before IA, determination of foetal lie, assessment of presentation and position before IA and identification of point of application of foetal stethoscope on maternal abdomen by $121(80.67 \%), 17(11.33 \%)$ and $34(22.67 \%)$ respectively; frequency of IA in the antenatal period, duration of IA and maternal pulse palpation during IA for $13-98(8.67-65.33 \%), 121(80 \%)$ and $0(0 \%)$ respectively; in labour, questions on timing of IA, ruling out hypoxia in early labour, determination of the baseline FHR and recording of the findings on IA for 61-130 (40.67-86.67\%); interval and duration of IA and management of abnormal findings in the antenatal period and in labour, interval and duration of IA at 2-18 (1.33-12\%).

Conclusions: The performance of IA by obstetric practitioners was poor; that may account for some of the wrong management plan in the antenatal and intra-partum periods. A quarterly or yearly drills on IA were therefore recommended.
\end{abstract}

Keywords: IA obstetric practice, Tertiary health facilities, Nigeria

\section{INTRODUCTION}

Intermittent auscultation (IA) is defined as the technique of listening to the fetal heart rate (FHR) for short periods of time without a display of the resulting pattern. It is performed with the aid of hand-held doppler ultrasound devices, e.g., sonicaid, cardiotocography (CTG), and a pinard fetal stethoscope. They detect fetal heart rate abnormalities and may in turn reduce the incidence of hypoxia / ischaemic outcome. ${ }^{1}$ Women who are healthy and have had an uncomplicated pregnancy are offered and recommended IA to monitor fetal well-being in labour. ${ }^{2}$
In Nigeria, the hand-held Doppler monitor and the electronic fetal monitors were rarely used in labour. The main fetal monitoring tool was the pinard stethoscope. The mean stillbirth rate in Nigeria was 39.6 per 1000 births (range: 12.7 to $67.3 / 1000$ births). ${ }^{[3]}$ Acute hypoxia in labour accounted for $32.6 \%$ of the stillbirths. ${ }^{3}$ Therefore accurately performed fetal monitoring in labour is an indispensable aspect of care in labour.

Auscultation of the FHR at each antenatal visit provides little information other than demonstrating that the fetus is alive but has no positive predictive value of fetal 
wellbeing. ${ }^{4,5}$ However, listening to the fetal heart at each antenatal visit may provide reassurance to the woman and her family. It was therefore recommended that a woman should be offered the opportunity to hear her baby's heart beat at each antenatal visit. ${ }^{4,5}$ There appear to be no good evidence from trials to recommend any particular frequency and duration of IA. Therefore, it was more a 'custom of practice' than 'evidence-based approach. ${ }^{6}$ However, the WHO guideline development group in 2018 agreed that standardization of protocol is important for health care planning and medico-legal purposes. ${ }^{1}$

\section{Aim}

The primary goal of the study was therefore to produce a standard protocol for IA in the antenatal period and in labour. The secondary goal was to determine whether IA was performed correctly or not in the two tertiary health facilities in Port Harcourt in Rivers State, Nigeria.

\section{METHODS}

The study was of mixed-method design including observational-descriptive, review and audit components. It was carried out in two tertiary health facilities in Rivers State, namely, university of Port Harcourt teaching hospital and Rivers State university teaching hospital from October to December 2019. The audit component included 150 participants-doctors, nurses and midwives that work in obstetric units in both tertiary centres. They were chosen because IA in the antenatal period and in labour was part of their daily job activities.

\section{Procedure}

The WHO 2018, FIGO 2015 guidelines and other guidelines on IA, were reviewed. Inclusion criterion for the literatures was that they should be on IA and related topics and published within the last 20 years. ${ }^{1,7,8}$ Good practice points as assessed by the research team were taken from the guidelines and used to form a working guideline as shown under 'Results.' The 17 review criteria for the audit were chosen from the guideline and used as questions to test the chosen 150 participants.

Out of the total number of the participants, 110 work in the obstetrics and gynaecology department of university of Port Harcourt teaching while 40 work in the Rivers State University teaching hospital. Professors, Nurse and midwives in the administrative positions who do little of clinical work were not sampled. The 150 medical personnel were more than $50 \%$ of the clinical workforce of both teaching hospitals and therefore the number was representative of the working population. Sampling of the candidates was systematic, starting first with the consultants, then resident trainees, and then midwives.

Questions were presented to the study population to answer during working hours without them making reference to literature in other to ascertain the true picture of the practice of IA $\mathrm{s}$ in the tertiary centres. Questions 14 dealt with the following respectively: the type of auscultating tool used in the antenatal clinic, ward and labour ward, assessment of fetal wellbeing 24 hours prior to IA, objective prerequisites before auscultation and knowledge of where to place the stethoscope on mother's abdomen, (Table 1). Other questions which focussed more on the antenatal period were used to assess the frequency of IA on the antenatal ward for high and low risk patients (questions 5 and 6), duration of auscultation in low-risk patients, including when the FHR was not in the normal range of 110-160 (questions 7 and 9) and management of abnormal results (question 10) (Table1 and 2).

Question 8 was about simultaneous palpation of maternal pulse when auscultating the foetal heart. Questions 11, 12, 13, 14 and 15 which focused on IA in labour were respectively used to assess the technique of obtaining baseline foetal heart rate, the timing, interval and duration of auscultation and the chance of ruling out chronic hypoxia. Question 16 dealt with the management of abnormality of the foetal heart rate while question 17 focussed on some other specific aspects of IA. The questions were as shown in tables 1 and 3 below.

\section{Ethical approval}

Ethical approval for the study was granted by university of Port Harcourt teaching hospital ethical committee.

\section{Statistics}

Data were entered in an excel file and then analysed, using Epi info 7.2.1 software package 2015 (epiinfo.reviewsoft.com). Simple proportions were used in the descriptive analysis.

\section{RESULTS}

The first aspect of the work was to write a guideline for IA for antenatal and intrapartum care. Number of articles identified through search $=65$. Number of articles dropped for duplication $=5$. Number of articles screened $=60$. Number of articles that did not meet the inclusion criteria and therefore dropped $=30$. Number of articles that met the inclusion criteria $=30$. Number of articles included in the reference $=15$. On the basis of the findings of literature review, a guideline on IA was formulated as shown in appendices 1 and 2 as shown below.

\section{Guideline on intermittent auscultation in labour}

The guideline on intermittent auscultation in labour are as follows: (a) ask about foetal movements over the preceding 24 hours; (b) determine lie, presentation and position of the baby; (c) on first auscultation listen for at least one 1 minute in between contractions when the baby is at rest to establish a baseline $\mathrm{FH}$ rate;(d) if in early labour, auscultate during fetal movements or following stimulation of the baby. Acceleration should be noted, and 
the presence of chronic hypoxia can be excluded; (e) the maternal pulse should be palpated simultaneously while auscultating FH. This should be done on the initiation of each auscultation and throughout if a $\mathrm{FH}$ abnormality is detected; (f) interval: Auscultate every 15-30 minutes in active first stage and passive second stage of labour, and every 5 minutes in the active second stage of labour; $(\mathrm{g})$ duration: each auscultation should last for at least 1 minute; if the FHR is not always in the normal range (i.e. 110-160 bpm), auscultation should be prolonged to cover at least three uterine contractions; (h) an observed rise in baseline rate, slow recovering decelerations or persistent accelerations (overshoot) after contractions should be confirmed by listening throughout the next 3 contractions to clarify the suspected pattern. Confirmation of an abnormality warrants a move to CEFM and an obstetrician (Senior Registrar, Experienced Registrar or a Medical officer) should be informed; (i) timing: auscultate during a uterine contraction and continue for at least 30 seconds after the contraction; (j) recording: (a) count the FH and document as a single number, and not as an average. If using a Doppler do not solely rely on the range shown on the screen, as there have been instances where the machine has miscalculated the $\mathrm{FH}$ rate, (b) secord acceleration and decelerations, if heard; and $(\mathrm{k})$ none of the literature suggests that variability can be determined by IA. ${ }^{2,9,11}$

\section{Guideline on IA of foetal heart in the antenatal period.}

Guideline on IA of foetal heart in the antenatal period as follows: (a) ask about foetal movements over the preceding 24 hours. Perform a full abdominal palpation to determine the lie, presentation and position of the baby; (b) apply the Pinard stethoscope or sonicaid on the mother's

Table 1: Questions 1-8 and answer options.

\begin{tabular}{|c|c|c|c|}
\hline S. no & Questions & Answers & Correct answers \\
\hline \multirow{3}{*}{1} & \multirow{3}{*}{$\begin{array}{l}\text { In most cases, what instrument do you use for } \\
\text { IA of fetal heart-pinard stethoscope or a } \\
\text { sonicaid? Please tick as applicable to you }\end{array}$} & $\begin{array}{l}\text { In the antenatal clinic: } \\
\text { i. Pinard. ii. stethoscope }\end{array}$ & 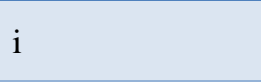 \\
\hline & & $\begin{array}{l}\text { Antenatal ward } \\
\begin{array}{ll}\text { i. Pinard ii. stethoscope }\end{array}\end{array}$ & $\mathrm{i}$ \\
\hline & & $\begin{array}{l}\text { On the labour ward } \\
\begin{array}{ll}\text { i. Pinard } & \text { ii. stethoscope }\end{array}\end{array}$ & $\mathrm{i}$ \\
\hline 2 & $\begin{array}{l}\text { Before auscultation, do you ask about fetal } \\
\text { movements at least } 24 \text { hours prior to that? }\end{array}$ & $\begin{array}{l}\text { a. Yes } \\
\text { b. No }\end{array}$ & $\mathrm{a}$ \\
\hline 3 & $\begin{array}{l}\text { Knowledge of following is indispensable for } \\
\text { correct auscultation. Please cycle correct ans. }\end{array}$ & $\begin{array}{ll}\text { a. Fetal lie } & \text { b. Presentation } \\
\text { c. Station } & \text { d. Position }\end{array}$ & $a, b, d$ \\
\hline 4 & $\begin{array}{l}\text { During IA where is the fetal heart sound best } \\
\text { heard? }\end{array}$ & $\begin{array}{l}\text { a. On the mother's abdomen in line } \\
\text { with the foetal scapula } \\
\text { b. On the mother's loin } \\
\text { c. On fetal back } \\
\text { d. On fetal loin }\end{array}$ & $\mathrm{a}, \mathrm{c}$ \\
\hline 5 & $\begin{array}{l}\text { For high-risk patients on the antenatal ward with } \\
\text { initial assessment showing normal heart rate, at } \\
\text { least how many times a day do you perform } \\
\text { auscultation? } \\
\text { Please tick the correct answer. }\end{array}$ & $\begin{array}{l}\text { a. } 1 \\
\text { b. } 2 \\
\text { c. } 3 \\
\text { d. } 4 \text { and more }\end{array}$ & $\mathrm{b}$ \\
\hline 6 & $\begin{array}{l}\text { For low-risk patients at booking on antenatal } \\
\text { ward with initial assessment showing normal }\end{array}$ & $\begin{array}{l}\text { a. } 1 \\
\text { b. } 2 \\
\text { c. } 3\end{array}$ & $\mathrm{~b}$ \\
\hline
\end{tabular}

Continued. abdomen in line with the foetal scapula to establish the sounds of the fetal heart (FH); (c) listen for at least one full minute; (d) the maternal pulse should be palpated simultaneously while auscultating FH if there is any concern about fetal heart rate; and (e) if any abnormality is and refer patient to the labour ward for CTG and further management.

The 150 obstetric practitioners from both tertiary centres in Port Harcourt, Rivers State of Nigeria answered the audit questions. The questions and their corresponding answers were itemised in Table 1 and 3 while the answers given by the participants to the questions were listed in Table 2 and 4.

All the participants answered questions $1 \mathrm{a}, \mathrm{b}$ and $\mathrm{c}$ correctly. $121(80.67 \%)$ out of the 150 participants answered the second question correctly while $28(18.67 \%)$ Of them did not know that they have to ask about fetal movements 24 hours prior to auscultation (Table 2).

Only $17(11.33 \%)$ of the obstetric Practitioners answered all the options for question 3 correctly-need to know the lie, position and presentation for accurate auscultation. 40 $(26.67 \%)$ ticked only lie, $34(22.67 \%)$ chose only presentation while $3(2 \%)$ chose only position. 34 $(22.67 \%)$ of the participants answered question 4 (the best place on maternal abdomen to listen to the fetal heart) correctly, i.e., "a' and 'c'" while 38 (25.33\%) ticked only 'a'" and another $38(25.33 \%)$ chose only 'c'" both of which were correct options. detected, please inform the Consultant or Senior Registrar 


\begin{tabular}{|c|c|c|c|}
\hline S. no & Questions & Answers & Correct answers \\
\hline & $\begin{array}{l}\text { heart rate, at least how many times day do you } \\
\text { perform auscultation? Please tick correct ans. }\end{array}$ & d. 4 and more & \\
\hline 7 & $\begin{array}{l}\text { In the antenatal period, how long do you listen } \\
\text { to the fetal heart beats }\end{array}$ & $\begin{array}{l}\text { a. } 15 \text { seconds and multiply by } 4 . \\
\text { b. } 1 \text { Minute } \\
\text { c. } 2 \text { Minutes } \\
\text { d. } 3 \text { Minutes }\end{array}$ & $\mathrm{b}$ \\
\hline 8 & $\begin{array}{l}\text { Maternal pulse should be palpated } \\
\text { simultaneously while auscultating FH }\end{array}$ & $\begin{array}{l}\text { a. Always when initiating auscultation } \\
\text { b. If there is any concern about foetal } \\
\text { heart rate }\end{array}$ & $a, b$ \\
\hline
\end{tabular}

Table 2: Performance of the candidates-answers to questions 1-8.

\begin{tabular}{|c|c|c|c|c|c|}
\hline Questions & $\begin{array}{l}\text { Correct } \\
\text { answers }\end{array}$ & $\begin{array}{l}\text { Number of } \\
\text { candidates }(\%)\end{array}$ & $\begin{array}{l}\text { Wrong } \\
\text { answers }\end{array}$ & $\begin{array}{l}\text { Number of candidates } \\
(\%)\end{array}$ & $\begin{array}{l}\text { Questions not } \\
\text { answered (\%) }\end{array}$ \\
\hline $1 a, b, c$ & $\mathrm{i}, \mathrm{i}, \mathrm{i}$ & $150(100)$ & I i, ii, ii. & $0(0)$ & $0(0)$ \\
\hline 2 & $\mathrm{a}$ & $121(80.67)$ & $\mathrm{b}$ & $28(18.67)$ & $1(0.67)$ \\
\hline \multirow{7}{*}{3} & $a, b, d$ & $17(11.33)$ & & & $4(2.7)$ \\
\hline & $\mathrm{a}, \mathrm{d}$ & $2(1.33)$ & & & \\
\hline & $\mathrm{b}, \mathrm{d}$ & $2(1.35)$ & & & \\
\hline & $\mathrm{d}$ & $3(2)$ & & & \\
\hline & $\mathrm{a}$ & $40(26.67)$ & & & \\
\hline & $a, b$ & $17(11.33)$ & & & \\
\hline & $\mathrm{b}$ & $34(22.67)$ & & & \\
\hline \multirow{3}{*}{4} & $\mathrm{a}, \mathrm{c}$ & $34(22.67)$ & $\mathrm{b}$ & $4(2.67)$ & $21(14)$ \\
\hline & c & $38(25.33)$ & $\mathrm{b}, \mathrm{d}$ & $4(2.67)$ & \\
\hline & $\mathrm{a}$ & $38(25.33)$ & $\mathrm{d}$ & $11(7.33)$ & \\
\hline \multirow{5}{*}{5} & b & $13(8.67)$ & $\mathrm{d}$ & $81(54)$ & $19(12.67)$ \\
\hline & c & $37(24.67)$ & & & \\
\hline & & & $a, d$ & $2(1.33)$ & \\
\hline & & & $\mathrm{c}, \mathrm{d}$ & $2(1.33)$ & \\
\hline & & & $\mathrm{a}$ & $6(4)$ & \\
\hline \multirow{3}{*}{6} & $\mathrm{~b}$ & $98(65.33)$ & $\mathrm{a}$ & $0(4)$ & $10(6.67)$ \\
\hline & & & $\mathrm{c}$ & $43(28.67)$ & \\
\hline & & & $\mathrm{d}$ & $29(19.33)$ & \\
\hline \multirow{3}{*}{7} & $\mathrm{~b}$ & $121(80)$ & $\mathrm{a}$ & $17(11.33)$ & $8(5.33)$ \\
\hline & & & $\mathrm{d}$ & $2(1.33)$ & \\
\hline & & & $\mathrm{c}$ & $2(1.33)$ & \\
\hline \multirow{3}{*}{8} & $a, b$ & $0(0)$ & & & $15(10)$ \\
\hline & $\mathrm{a}$ & $84(56)$ & & & \\
\hline & b & $51(34)$ & & & \\
\hline
\end{tabular}

Table 3: Questions 9-17 and answer options.

\begin{tabular}{|c|c|c|c|}
\hline S. no. & Questions & Answers & $\begin{array}{l}\text { Correct } \\
\text { answers }\end{array}$ \\
\hline 9 & During IA & $\begin{array}{l}\text { a. Record only the fetal heart rate } \\
\text { b. Record fetal heart rate, acceleration and decelerations } \\
\text { c. Baseline variability is easily determined. }\end{array}$ & $\mathrm{b}$ \\
\hline 10 & $\begin{array}{l}\text { In the antenatal clinic, if the } \\
\text { FHR continues to be } \\
\text { abnormal, what do you do? }\end{array}$ & $\begin{array}{l}\text { a. Auscultate the heart again the third time } \\
\text { b. Inform the Registrar, Senior Registrar or Consultant. } \\
\text { c. Refer the Patient to the labour ward for CTG and further } \\
\text { management }\end{array}$ & $\mathrm{b}, \mathrm{c}$ \\
\hline 11 & $\begin{array}{l}\text { In labour, on first } \\
\text { auscultation, how do you } \\
\text { establish the baseline rate? }\end{array}$ & $\begin{array}{l}\text { a. Listen for at least one } 1 \text { minute in between contractions when } \\
\text { the baby is at rest } \\
\text { b. Listen for at least one } 2 \text { minutes in between contractions } \\
\text { when the baby is at rest } \\
\text { c. Listen for at least } 2 \text { minutes when there are } \\
\text { d. contractions }\end{array}$ & $\mathrm{a}$ \\
\hline
\end{tabular}




\begin{tabular}{|c|c|c|c|}
\hline S. no. & Questions & Answers & $\begin{array}{l}\text { Correct } \\
\text { answers }\end{array}$ \\
\hline 12 & $\begin{array}{l}\text { In early labour, how do you } \\
\text { rule out fetal chronic } \\
\text { hypoxia? }\end{array}$ & $\begin{array}{l}\text { a. Auscultation during foetal movements or following } \\
\text { stimulation of the baby shows acceleration. } \\
\text { b. Auscultate between fetal movements is necessary }\end{array}$ & $\mathrm{a}$ \\
\hline 13 & $\begin{array}{l}\text { Timing of auscultation in } \\
\text { labour }\end{array}$ & $\begin{array}{l}\text { a. Auscultate between uterine contractions and continue for at } \\
\text { least } 60 \text { seconds. } \\
\text { b. Auscultate during a uterine contraction and continue for at } \\
\text { least } 30 \text { seconds after the contraction }\end{array}$ & b \\
\hline 14 & $\begin{array}{l}\text { Interval of auscultation in } \\
\text { labour-Please tick as } \\
\text { necessary }\end{array}$ & $\begin{array}{l}\text { a. Every } 50 \text { minutes in active first stage: } \\
\text { b. Every } 15-30 \text { minutes in active first stage and passive second } \\
\text { stage of labour. } \\
\text { c. Every } 40 \text { minutes in active first stage } \\
\text { d. Every } 10-30 \text { minutes in the passive second stage of labour } \\
\text { e. Every } 5 \text { minutes in the active second stage of labour. } \\
\text { f. Every } 10 \text { minutes in the active second stage of labour. }\end{array}$ & $\mathrm{b}, \mathrm{e}$ \\
\hline 15 & $\begin{array}{l}\text { Duration of auscultation in } \\
\text { labour }\end{array}$ & $\begin{array}{l}\text { a. At least } 1 \text { minute: } \\
\text { b. } 2 \text { minutes } \\
\text { c. If the FHR is not always in the normal range (i.e., 110-160 } \\
\text { bpm), ascultation should be prolonged to cover at least two } \\
\text { uterine contractions. } \\
\text { d. If the FHR is not always in the normal range (i.e., 110-160 } \\
\text { bpm), auscultation should be prolonged to cover at least three } \\
\text { uterine contractions. }\end{array}$ & $\mathrm{a}, \mathrm{d}$ \\
\hline 16 & $\begin{array}{l}\text { What do you do immediately } \\
\text { when the fetal heart rate is } \\
\text { abnormal? }\end{array}$ & $\begin{array}{l}\text { a. Move to CTG monitoring } \\
\text { b. Do caesarean section immediately } \\
\text { c. Perform intrapartum fetal resuscitation } \\
\text { d. Inform a Senior Colleague }\end{array}$ & $\mathrm{a}, \mathrm{c}, \mathrm{d}$ \\
\hline 17 & $\begin{array}{l}\text { Please tick the correct } \\
\text { statement related to labour. }\end{array}$ & $\begin{array}{l}\text { a. When using a pinard stethoscope, count the FHR and } \\
\text { document as a single number } \\
\text { b. When using a pinard stethoscope, count the FHR for } 15 \\
\text { mins and multiply by } 4 \\
\text { c. When using a Doppler do not solely rely on the range } \\
\text { shown on the screen } \\
\text { d. Baseline variability can always be determined by IA. }\end{array}$ & $\mathrm{a}, \mathrm{c}$ \\
\hline
\end{tabular}

S/N-Serial numbers; CA-Correct answers.

Table 4: Performance of the candidates-answers to questions 9-17.

\begin{tabular}{|c|c|c|c|c|c|}
\hline Questions & $\begin{array}{l}\text { Correct } \\
\text { answers }\end{array}$ & $\begin{array}{l}\text { Number of } \\
\text { candidates }(\%)\end{array}$ & $\begin{array}{l}\text { Wrong } \\
\text { answers }\end{array}$ & $\begin{array}{l}\text { Number of } \\
\text { candidates }(\%)\end{array}$ & $\begin{array}{l}\text { Questions not } \\
\text { answered (\%) }\end{array}$ \\
\hline \multirow{2}{*}{9} & $\mathrm{~b}$ & $130(86.67)$ & a & $10(6.67)$ & $5(3.33)$ \\
\hline & & & $\mathrm{c}$ & $5(3.33)$ & \\
\hline \multirow{3}{*}{10} & $\mathrm{~b}, \mathrm{c}$ & $2(1.33)$ & $\mathrm{a}$ & $3(2)$ & $10(6.67)$ \\
\hline & $\mathrm{b}$ & $63(42)$ & & & \\
\hline & $\mathrm{c}$ & $72(48)$ & & & \\
\hline \multirow{2}{*}{11} & $\mathrm{a}$ & $97(64.67)$ & $\mathrm{b}$ & $21(14)$ & $19(12.67)$ \\
\hline & & & $\mathrm{c}$ & $13(8.67)$ & \\
\hline 12 & $\mathrm{a}$ & $70(46.67)$ & $\mathrm{b}$ & $46(30.67)$ & $34(22.67)$ \\
\hline 13 & $\mathrm{~b}$ & $61(40.67)$ & $\mathrm{a}$ & $79(52.67)$ & $10(6.67)$ \\
\hline \multirow{4}{*}{14} & $\mathrm{~b}, \mathrm{e}$ & $18(12)$ & $\mathrm{c}$ & $22(14.67)$ & \\
\hline & $\mathrm{b}$ & $59(39.33)$ & $\mathrm{a}$ & $21(14)$ & \\
\hline & $\mathrm{e}$ & $14(9.36)$ & $a, f$ & $64(4)$ & \\
\hline & & & d & $10(6.67)$ & \\
\hline \multirow{2}{*}{15} & $\mathrm{a}, \mathrm{d}$ & $18(12)$ & $\mathrm{c}$ & $25(16.67)$ & $4(2.67)$ \\
\hline & $\mathrm{a}$ & $95(63.33)$ & $\mathrm{b}$ & $8(5.33)$ & \\
\hline \multirow{3}{*}{16} & $\mathrm{a}, \mathrm{c}, \mathrm{d}$ & $2(1.3)$ & $\mathrm{b}$ & $17(11.33)$ & $96(6)$ \\
\hline & a & $60(30)$ & & & \\
\hline & $\mathrm{d}$ & $38(25.33)$ & & & \\
\hline
\end{tabular}

Continued. 


\begin{tabular}{|c|c|c|c|c|c|}
\hline Questions & $\begin{array}{l}\text { Correct } \\
\text { answers }\end{array}$ & $\begin{array}{l}\text { Number of } \\
\text { candidates }(\%)\end{array}$ & $\begin{array}{l}\text { Wrong } \\
\text { answers }\end{array}$ & $\begin{array}{l}\text { Number of } \\
\text { candidates }(\%)\end{array}$ & $\begin{array}{l}\text { Questions not } \\
\text { answered (\%) }\end{array}$ \\
\hline \multirow{5}{*}{17} & $\mathrm{a}, \mathrm{d}$ & $4(2.67)$ & & & \\
\hline & $\mathrm{c}$ & $19(12.67)$ & & & \\
\hline & $\mathrm{a}, \mathrm{c}$ & $12(8)$ & $\mathrm{b}$ & $37(14.67)$ & 23 \\
\hline & $\mathrm{a}$ & $26(17.33)$ & $\mathrm{d}$ & $27(18)$ & \\
\hline & $\mathrm{c}$ & $25(16.67)$ & & & \\
\hline
\end{tabular}

\section{DISCUSSION}

The present study was prompted by an observation when working on the labour ward. There were visible variations when medical staff carry out IA of foetal heart in the antenatal clinic and ward and the labour ward. ${ }^{1,2,5,8,14}$ It was therefore hypothesised that, in some instances, they may not be doing it correctly. Although predicted, the achieved result was far worse than expected.

The $28(18.67 \%)$ out of the 150 obstetric practitioners did not know that they had to assess foetal wellbeing by asking a question about foetal movements 24 hours prior to auscultation. Only 17 participants $(11.11 \%)$ knew the complete answers to the question on the prerequisites for correct auscultation, namely knowledge of foetal presentation, lie and position. The point on maternal abdomen where the foetal heart sound was best heard was also called into question because only 34 (22.67\%) out of the 150 participants got the full answer right.

There was also a big question mark on the knowledge of IA in the antenatal period. The answers given by the participants to questions assessing frequency, duration of auscultation and management of abnormal foetal heart rates were alarming (Questions 5, 6, 7 and 10).

The 17 (11.33\%) out of the 150 participants did not know that during the antenatal period, the duration of auscultation was 1 minute. $8(5.33 \%)$ of the candidates did not answer that question at all. Only $13(8.67 \%)$ and 98 (65.33) of the 150 participants knew that the least frequency of auscultation of FHR on the antenatal ward for stable high risk and low risk patients respectively was twice daily. Only 2 obstetric practitioners $(1.33 \%)$ out of the 150 participants ticked the complete correct options (informing a senior doctor and transfer to delivery suit) for management of abnormal antenatal foetal heart rate.

The answers to the question number 8 were also not expected. It was on whether the maternal pulse should be palpated simultaneously when starting IA and when there was any concern about foetal heart rate. The correct answer was "yes" for both options. . $, 2,7,10^{1}$ Unfortunately, none of the participants got the 2 option right. Only $56 \%$ and $34 \%$ of them respectively got option one and two right. Question 9 was on recording of the findings after IA. 130 $(86.67 \%)$ of the 150 participants answered the question correctly, i.e., baseline foetal heart rate, accelerations and deceleration should be recorded. The $10(6.67 \%)$ of the 150 participants believe that only the FHR should be recorded and $5(3.33 \%)$ believed that foetal heart baseline variability could easily be assessed during IA. Both answers were wrong. Shortcomings might be responsible for high prevalence of birth asphyxia in Nigeria. ${ }^{13}$

Other questionable performances were shown in questions that were used to assess knowledge of the technique to establish the baseline fetal heart rate, rule out chronic hypoxia and the timing, interval and duration of auscultation in labour (Questions 11, 12, 13, 14, 15). In question $11,34(22.67 \%)$ of the 150 participants did not realise that in labour, the baseline foetal heart rate should be determined by auscultating between contraction. 19 (12.67\%) participants did not answer that question at all. Regarding ruling out foetal chronic hypoxia in early labour, $46(30.67 \%)$ of the 150 participants did not know that they should elicit that by auscultating during foetal movement or when the fetus was stimulated (Question 12); Positive response would be acceleration of the baseline rate. ${ }^{1} 34$ participants $(22.67 \%)$ did not answer that question at all.

It was equally shocking that only $61(40.67 \%)$ out of the 150 participants knew about timing of auscultation in labour (question 13), that IA should be started during uterine contraction and continue for at least 30 seconds after the contraction.

$89(59.33 \%)$ did not know that. Another finding that was unbelievable was the answers to question 14 . Only 18 (12\%) of the 150 participants knew that auscultation should be performed every 15-30 minutes in the active first stage and passive second stage of labour and every 5 minutes in the active second stage. The 59 (39.33\%) of the participants got only the first part of the answers right while $14(9.36 \%)$ got only the second correct. The 59 $(39.33 \%)$ answered the question completely wrong.

Regarding duration of auscultation (question 15), only 18 $(12 \%)$ of the 150 participants got both answers rightduration of auscultation in labour of $1 \mathrm{~min}$ but if the FHR was not always in the normal range (i.e., 110-160 bpm), auscultation should be prolonged to cover at least three uterine contractions. ${ }^{1,2}$ The second part of the correct answers was achieved by 95 (63.33\%) obstetric practitioners.

The answer to question 16 on the immediate management of abnormal finding in labour was not encouraging. Only 2 out of the entire participants $(1.3 \%)$ got the 3 correct options namely, 'conversion to CTG monitoring', 'performing intrapartum foetal resuscitation' and 'to inform a senior colleague'. ${ }^{1,2}$ 
Furthermore, $17(11.33 \%)$ chose to perform caesarean section immediately. Question 17 was on the actual process of counting the foetal heart rate.

Only $12(8 \%)$ of the 150 candidates ticked the correct 2 options which were as following: 'a. when using a pinard stethoscope, count the FHR and document as a single number"' and 'c. When using a hand-held doppler do not solely rely on the range shown on the screen." Again, it was quite surprising that $37(14.67 \%)$ of the candidates counted the FHR for 15 mins and multiply it by 4 and 27 $(18 \%)$ did not know that baseline variability in labour could not be determined accurately by IA. The poor performance, regarding the tests on performing IA both in the antennal period and in labour might be responsible for significant prevalence of fetal hypoxia and perinatal morbidity and mortality in Nigeria. ${ }^{3,14,15}$

The main limitation of the study was that it was not conducted nationwide and therefore the results might not be entirely extrapolated to the whole of Nigeria.

\section{CONCLUSION}

The findings clearly demonstrated the poor performance of obstetric practitioners in carrying out IA in the antenatal period and in labour. That may account for some of the wrong decisions of doing caesarean section for foetal distress in labour which was common in low-resource setting. It may also account for the many cases of undiagnosed foetal hypoxia in labour and chronic hypoxia in the antenatal clinic. IA was such an indispensable tool in obstetric practice in low-resource settings that every obstetric Practitioner must master.

\section{Recommendations}

We recommend that every obstetric unit should consider including IA of the foetal with a hand-held doppler or pinard stethoscope as part of a routine obstetric drills (alongside shoulder dystocia, breech in labour, eclampsia and others) that are normally conducted quarterly, every 6 months or yearly. Furthermore, in view of the diversities in the techniques of performing IA, we recommend the adoption of the modified into a singular protocol, the 2018 WHO and the FIGO 2015 guideline on IA which was used in the present study.

Funding: No funding sources Conflict of interest: None declared

Ethical approval: The study was approved by the Institutional Ethics Committee

\section{REFERENCES}

1. WHO recommendation on intermittent fetal heart rate auscultation during labour. The WHO Reproductive Health Library; Geneva: World Health Organization. 2018.
2. National Institute for Health and Care Excellence. Intrapartum care: care of healthy women and their babies during childbirth NICE clinical guideline 190. 2014.

3. Okonofua FE, Ntoimo LFC, Ogu R, Galadanci H, Mohammed G, Adetoye D et. Al. Prevalence and determinants of stillbirth in Nigerian referral hospitals: a multicentre study. BMC Pregnancy Childbirth. 2019;19:533.

4. Alfirevic Z, Devane D, Gyte GM, Anna Cuthbert. Continuous cardiotocography (CTG) as a form of electronic fetal monitoring (EFM) for fetal assessment during labour. Cochrane Database Syst Rev. 2017;3:2(2):CD006066.

5. Vintzileos AM, Nochimson DJ, Guzman ER, Knuppel RA, Lake M, Schifrin BS. Intermittent electronic fetal heart rate monitoring versus intermittent auscultation: a meta-analysis. Obstet Gynecol. 1995;85:149-55.

6. Walsh D. CTG use in intrapartum care: assessing the evidence. Bri J Midwifery. 2008;16(6):367-9.

7. Diogo Ayres-de-Campos, Catherine Y. Spong, Edwin Chandraharan, for the FIGO intrapartum fetal monitoring consensus panel. FIGO consensus guidelines on intrapartum fetal monitoring. Int $\mathbf{J}$ Gynaecol Obstet. 2015

8. Chandraharan E. Intrapartum Fetal Monitoring Guideline. Physiological CTG interpretation. 2018.

9. Munro J, Jokinen M: Evidence based guidelines for Midwifery-led Care in labour. Intermittent Auscultation (IA). The Royal College of Midwives Trust. 2012.

10. National Collaborating Centre for Women's and Children's Health Intrapartum care: care of healthy women and their babies during childbirth. RCOG Press: London. 2007.

11. Medicines and Healthcare products Regulatory Agency. Medical safety alert: Fetal monitor/cardiotocography (CTG)-All adverse outcomes are still reported when CTG traces appear normal, 2010. Available at: https://assets.publishing.service.gov.uk/media/5485a c34e5274a428d00028f/con085077.pdf. Accessed on 25 October 2021.

12. Royal College of Obstericts and Gynecology. Intermittent auscultation: Key recommendations. RCOG. 2015;1-88.

13. Egharevba OI, Kayode-Adedeji BO, Alikah SO. Perinatal asphyxia in a rural Nigerian hospital: Incidence and determinants of early outcome. J Neonatal Perinatal Med. 2018;11(2):179-183.

14. Oladapo OT, Adetoro OO, Ekele BA, Chama C, Etuk SJ, Aboyeji AP, et al. Nigeria Near-miss and Maternal Death Surveillance Network. When getting there is not enough: a nationwide cross-sectional study of 998 maternal deaths and 1451 near-misses in public tertiary hospitals in a low-income country. BJOG. 2016;123:928-38.

15. Akinyemi J, Bamgboye E, Ayemi O. Trends in neonatal mortality in Nigeria and effects of 
biodemographic and maternal characteristics. BMC

Peddiatr. 2015;15:36.

Cite this article as: Kinikanwo G, Abbey M, Ela

GM. Intermittent auscultation in obstetric practice in tertiary health facilities in Nigeria. Are we doing it correctly? Int J Reprod Contracept Obstet Gynecol 2022;11:7-14. 